University of Nebraska - Lincoln

DigitalCommons@University of Nebraska - Lincoln

$1-2018$

New evidence of ancient parasitism among Late Archaic and Ancestral Puebloan residents of Chaco Canyon

Rachel E. Paseka

Carrie C. Heitman

Karl Reinhard

Follow this and additional works at: https://digitalcommons.unl.edu/natresreinhard

Part of the Archaeological Anthropology Commons, Ecology and Evolutionary Biology Commons, Environmental Public Health Commons, Other Public Health Commons, and the Parasitology Commons

This Article is brought to you for free and open access by the Natural Resources, School of at DigitalCommons@University of Nebraska - Lincoln. It has been accepted for inclusion in Karl Reinhard Papers/ Publications by an authorized administrator of DigitalCommons@University of Nebraska - Lincoln. 


\title{
New evidence of ancient parasitism among Late Archaic and Ancestral Puebloan residents of Chaco Canyon
}

\author{
Rachel E. Paseka, ${ }^{1}$ Carrie C. Heitman, ${ }^{2}$ \\ and Karl J. Reinhard ${ }^{3}$
}

1 Graduate Program in Ecology and Evolution, Department of Ecology, Evolution, and Natural Resources, Rutgers, The State University of New Jersey, 14 College Farm Road, New Brunswick, NJ 08901, United States 2 Department of Anthropology, University of Nebraska-Lincoln, 833 Oldfather Hall, PO Box 880368, Lincoln, NE 68588-0368, United States

3 School of Natural Resources, 719 Hardin Hall, 3310 Holdrege Street, Lincoln, NE 68583-0987, United States

Corresponding author - Rachel E. Paseka

Email addresses: rachel.paseka@rutgers.edu (R.E. Paseka), cheitman2@unl.edu (C.C. Heitman), kreinhard1@unl.edu (K.J. Reinhard).

\begin{abstract}
Archaeoparasitology provides a unique perspective on the health and habits of ancient cultures through the identification of parasite remains in archaeological materials. We identified eggs of the human whipworm, Trichuris trichiura, in coprolites recovered from Late Archaic (1926-1751 cal. BCE) and Ancestral Puebloan (1039-1163 cal. CE) sites in Chaco Canyon, New Mexico. Our findings represent the earliest record of $T$. trichiura in North America, the first record of the species from Chaco Canyon, and the first record of a macroparasite from a Late Archaic site (Atlatl Cave) on the Colorado Plateau. T. trichiura is common in the global archaeoparasitology record, but until now it was not known to have infected Ancestral Puebloans.
\end{abstract}

Published in Journal of Archaeological Science: Reports 18 (2018) 51-58

doi:10.1016/j.jasrep.2018.01.001

Copyright (C) 2018 Elsevier Ltd. Used by permission.

Submitted 4 May 2017; revised 23 December 2017; accepted 4 January 2018; published

9 January 2018. 
Environmental barriers to transmission and lack of contact with infected Mesoamerican cultures have previously been used to explain the absence of this species from the Southwest. The new evidence of $T$. trichiura presented here raises questions about the cultural context which led to the arrival and persistence of this parasite in both a Late Archaic cave and an Ancestral Puebloan great house at Chaco Canyon. We propose that the moisture requirements of $T$. trichiura transmission may have been met through anthropogenic modification of the local environment, and that the presence of this species at Chaco Canyon suggests contact with infected Mesoamerican cultures. We also report the presence of the pinworm, Enterobius vermicularis, and unidentified larval nematodes in the Chaco Canyon archaeological record.

Keywords: Archaeoparasitology, Atlatl Cave, Chaco Canyon, Coprolite, Pueblo Bonito, Trichuris trichiura, Whipworm

\section{Introduction}

Parasite remains identified from archaeological materials provide a unique lens on the health, culture, and ecology of human hosts (Reinhard, 1992). This archaeoparasitological perspective has been especially important in the American Southwest, where the arid climate has led to excellent preservation of parasite eggs and larvae in coprolites from many sites (e.g., Reinhard and Bryant, 2006). Parasites provide information about ancient Southwestern health (Reinhard, 2008a), diet (Fry, 1977; Reinhard et al., 1987), migration (Jiménez et al., 2012; Reinhard et al., 1987), and cultural transitions (Hugot et al., 1999; Reinhard, 1988).

Parasitic infection was common at Ancestral Puebloan sites, where sedentary lifestyles, concentrated populations, irrigation, and communal latrines likely facilitated parasite transmission (Reinhard, 2008a). Substantial variation in the levels of parasitism documented among Ancestral Puebloan sites suggests that local conditions and practices determined disease prevalence. For example, eggs from the pinworm, Enterobius vermicularis, were common in a prior analysis of coprolites from Chaco Canyon, New Mexico (Reinhard and Clary, 1986). Pinworm thrives in dense host populations, so its presence at Chaco Canyon suggests that residents experienced crowded living conditions. Although pinworm is not particularly pathogenic, its presence suggests that other infectious diseases caused by parasites and pathogens transmitted through a fecal-oral route may also have occurred at Chaco Canyon. 
We conducted parasitological analysis of 19 coprolites from one Late Archaic (Atlatl Cave) and three Ancestral Puebloan (Pueblo Bonito, Kin Kletso and Pueblo Alto) sites within Chaco Canyon, NM. Our aims were to expand upon earlier archaeoparasitology research from Chaco Canyon (Reinhard and Clary, 1986) by analyzing coprolites from additional sites and periods of occupancy and to contribute to broader knowledge of Southwestern archaeoparasitology.

Chaco Canyon was extensively settled by the ancestors of contemporary Pueblo people. Today, its widespread sphere of prehispanic influence makes it one of the most important archaeological regions in North America. Chaco Canyon is recognized as a National Park and a UNESCO World Heritage Site. During the Archaic (5500-3200 BCE) and the Late Archaic (3000-800 BCE), inhabitants of Chacon Canyon transitioned from mixed gathering and hunting economies to mixed foraging subsistence (Mathien, 2005). By most accounts, the canyon was used seasonally (late spring-early fall) in a limited or sporadic way (Elliott, 1986). Elliott (1986) argues that the water catchments in Chaco Canyon aided maize horticulture and seasonal sedentism, although maize (along with squash) was a minor component of a mixed subsistence base during the Late Archaic. Irwin-Williams (1973) identified larger, seasonal aggregations during this period, possibly consisting of groups between 30 and 50 individuals.

A profound social transformation took place in Chaco Canyon between 800 and $1100 \mathrm{CE}$, resulting in unprecedented construction of massive masonry buildings (great houses) located within a dense and central "downtown" precinct. Seventeen multi-story great houses (50650 rooms; Lekson, 1984) along with numerous great kivas (circular communal structures) were erected within a crowded nine-mile stretch of the canyon. These large structures were surrounded by hundreds of more modestly built small houses along the Chaco Wash (McKenna and Truell, 1986). Research in recent decades has connected this apparent core of great house and small house sites in Chaco Canyon to an expansive network of roads (Kincaid, 1983; Marshall et al., 1979; Nials et al., 1987; Powers et al., 1983) and approximately 290 outlying great house communities (Heitman et al., 2016) over an $110,000 \mathrm{~km}^{2}$ area of the northern Southwest. Material signatures of the Chacoan culture or its influence can be found across the Four Corners states (Colorado, New Mexico, Arizona and Utah) in an area as 
large as Ireland. During the peak of its florescence, canyon inhabitants participated in long-distance trade networks to obtain materials such as copper bells (Toll, 1991), macaws (Watson et al., 2015), turquoise (Hull et al., 2014), shell (Mills and Ferguson, 2008), chert (Cameron, 2001), obsidian (Duff et al., 2012) and cacao (Crown and Hurst, 2009).

Our parasitological analyses of Chaco Canyon coprolites revealed that both Late Archaic and later prehispanic residents were infected with the human whipworm, Trichuris trichiura, which represents the earliest known record of the species in North America. Whipworm has generally been considered a Mesoamerican species in antiquity, and it has not been detected previously on the Colorado Plateau despite extensive analysis of coprolites from the region (Gonçalves et al., 2003). These new records of $T$. trichiura at both a Late Archaic cave and a Puebloan great house raise questions as to what events led to the arrival of this species at Chaco Canyon and what conditions allowed it to persist. We also report the presence of the pinworm, Enterobius vermicularis, and unidentified larval nematodes in the archaeological record of Chaco Canyon.

\section{Materials and methods}

We obtained 19 coprolites from previous archaeological work in Chaco Canyon National Historic Park, New Mexico. These samples were originally analyzed as part of the Chaco Project in the 1980s (Clary, 1987, 1984, 1983; Toll, 1981). Fragments of these coprolites had been curated in the Laboratory of Palynology and Pathoecology, University of Nebraska-Lincoln. The samples have since been returned to the Chaco Center, Hibben Institute, University of New Mexico. The coprolites analyzed in this study represent four sites that differ in period of occupancy and dwelling size, all of which are located within a one-kilometer radius in Chaco Canyon. Fourteen coprolites were from Chacoan great houses: Pueblo Bonito (10), Pueblo Alto (2), and Kin Kletso (4), and three coprolites were from Atlatl Cave, a Late Archaic site (Table 1).

Prior stratigraphic dating suggests that the Pueblo Bonito samples were deposited from to $1080-1130 \mathrm{CE}$, the Pueblo Alto coprolites date from 1050 to $1100 \mathrm{CE}$, and the Kin Kletso coprolites were from 1100 
Table 1 Coprolites analyzed in this study. Dates marked with (1) indicate stratigraphic dates reported by Clary (1984). Dates marked with (2) indicate stratigraphic dates reported by Reinhard and Clary (1986). Dates marked with a (3) indicate calibrated AMS radiocarbon dates for that sample. Sample 1 from Atlatl Cave was observed to be non-biological material upon rehydration.

\begin{tabular}{|c|c|c|c|}
\hline Sample \# & Site & Date & Contents \\
\hline 1 & Atlatl Cave & Non-coprolite & \\
\hline 2 & Atlatl Cave & $1926-1751 \mathrm{cal} . \mathrm{BCE}^{3}$ & $\begin{array}{l}\text { Trichuris trichiura; } \\
\text { unidentified nematode larvae }\end{array}$ \\
\hline 3 & Atlatl Cave & & \\
\hline 4 & Pueblo Bonito & 1039-1164 cal. $\mathrm{CE}^{3}$ & Enterobius vermicularis \\
\hline 5 & Pueblo Bonito & $1080-1130 \mathrm{CE}^{1}$ & Unidentified nematode larvae \\
\hline 6 & Pueblo Bonito & $1080-1130 \mathrm{CE}^{1}$ & Unidentified nematode larvae \\
\hline 7 & Pueblo Bonito & $1080-1130 \mathrm{CE}^{1}$ & \\
\hline 8 & Pueblo Bonito & $1164-1252$ cal. $\mathrm{CE}^{3}$ & \\
\hline 9 & Pueblo Bonito & $1046-1219$ cal. $\mathrm{CE}^{3}$ & \\
\hline 10 & Pueblo Bonito & $1080-1130 \mathrm{CE}^{1}$ & \\
\hline 11 & Pueblo Bonito & $1080-1130 \mathrm{CE}^{1}$ & \\
\hline 12 & Pueblo Bonito & $1039-1163$ cal. $\mathrm{CE}^{3}$ & Trichuris trichiura \\
\hline 13 & Pueblo Bonito & $1187-1264$ cal. $\mathrm{CE}^{3}$ & \\
\hline 14 & Pueblo Alto & & \\
\hline 15 & Pueblo Alto & $1050-1100 \mathrm{CE}^{1}$ & \\
\hline 16 & Kin Kletso & $1100-1150 \mathrm{CE}^{2}$ & Enterobius vermicularis \\
\hline 17 & Kin Kletso & $1100-1150 \mathrm{CE}^{2}$ & \\
\hline 18 & Kin Kletso & $1100-1150 \mathrm{CE}^{2}$ & \\
\hline 19 & Kin Kletso & $1154-1254$ cal. $\mathrm{CE}^{3}$ & \\
\hline
\end{tabular}

to 1150 CE (Clary, 1984; Reinhard and Clary, 1986). For this study, we obtained eight Accelerator Mass Spectrometer (AMS) radiocarbon dates from seven coprolites (Table 2). Two dates were run on a sample from a single coprolite recovered from Atlatl Cave. This sample was separated into larger (macrobotanicals $>250 \mu$ ) and smaller (microbotanicals $<250 \mu$ and feces) fractions in order to obtain multiple dates. Of these two dates, we are more confident of the macrobotanical fraction (D-AMS 015356, Table 2). Six samples from two great house sites (Pueblo Bonito and Kin Kletso) were also dated (Table 2). All samples underwent standard acid-base-acid pre-treatment protocols prior to measurement of carbon isotopes by AMS and subsequent data analysis. Radiocarbon assays were then calculated using OxCal v4.2.4 (Bronk Ramsey, 2013). Before beginning parasite analysis, we visually examined each coprolite and observed no evidence for fungal growth or bore holes from free-living arthropods or nematodes. We 


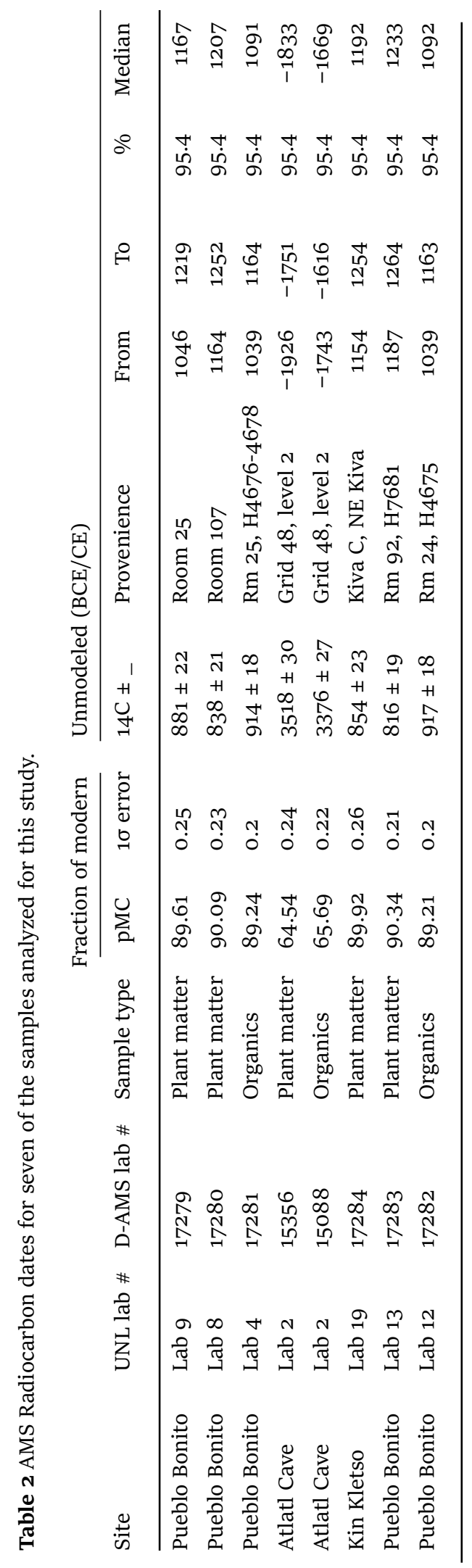


rehydrated coprolites following standard paleoparasitological methods (Callen and Cameron, 1960; Reinhard et al., 1986), also preserving a desiccated portion of each coprolite. We weighed each dry sample and soaked it in a $0.5 \%$ trisodium phosphate solution for 24-72 $\mathrm{h}$. The light color of rehydration fluid and subsequent microscopic analysis indicated that one sample from Atlatl Cave was of geological nature. Dark rehydration fluid indicated human origins for all other samples (Reinhard and Bryant, 1992). Once rehydrated, we disaggregated coprolites with a magnetic stirrer and added one Lycopodium tablet dissolved in hydrochloric acid to each sample. Each tablet contained a known number of club moss spores identifiable by microscopic analysis, allowing the density of spores and parasite eggs to be quantitatively compared among samples. We screened and centrifuged the rehydrated samples to concentrate microscopic remains, including parasites, then preserved samples in 70\% ethanol.

To identify and quantify parasite remains, we mounted processed fecal material with a drop of glycerine on glass slides. We examined a minimum of 15 slides per sample with light microscopy, counting all parasite remains and Lycopodium spores observed. We photographed all parasite remains and identified them morphologically (Thienpont et al., 1979).

\section{Results}

Two coprolites contained eggs of the human whipworm, Trichuris trichiura, one from Atlatl Cave (24 eggs/g of coprolite) and one from Pueblo Bonito (29 eggs/g) (Table 1). Trichuris eggs are recognizable by their polar plugs and smooth outer shells (Fig. 1). T. trichiura can be distinguished from its congeners by egg dimensions (Table 3; Thienpont et al., 1979), which remain consistent despite desiccation (Confalonieri et al., 1985).

Two coprolites contained eggs of the human pinworm, Enterobius vermicularis, one from Pueblo Bonito (16 eggs/g) and one from Kin Kletso (106 eggs/g). The eggs were easily recognizable by size and morphology (Fig. 2), though preservation was poor.

One coprolite from Atlatl Cave and two from Pueblo Bonito also contained unidentified nematode larvae. These nematodes resemble 


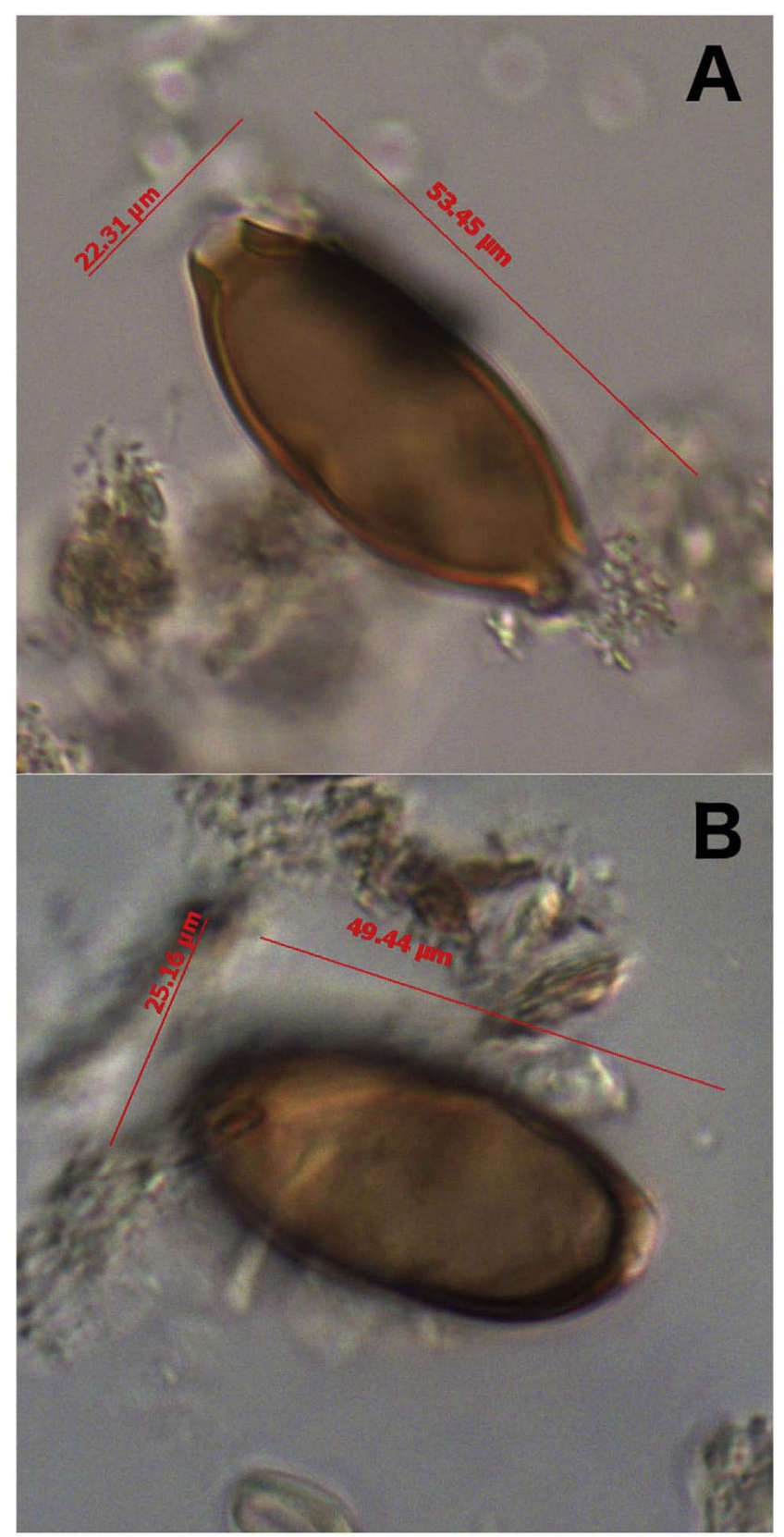

Fig. 1. Trichuris trichiura eggs from Atlatl Cave (a) and Pueblo Bonito (b). Eggs of this species are easily identifiable by their polar plugs and overall dimensions.

Table 3 Egg dimensions for Trichuris trichiura and other Trichuris species commonly associated with humans (Thienpont et al., 1979).

\begin{tabular}{llll} 
Parasite species & Host & Length $(\mu)$ & Width $(\mu)$ \\
\hline T. trichiura & Humans & $50-58$ & $22-27$ \\
$T$. muris & Rodents & $67-70$ & $31-34$ \\
$T$. vulpis & Dogs & $70-90$ & $32-41$ \\
$T$. suis & Pigs & $50-68$ & $21-31$ \\
$T$. ovis & Cattle, sheep & $70-80$ & $30-42$ \\
\hline
\end{tabular}




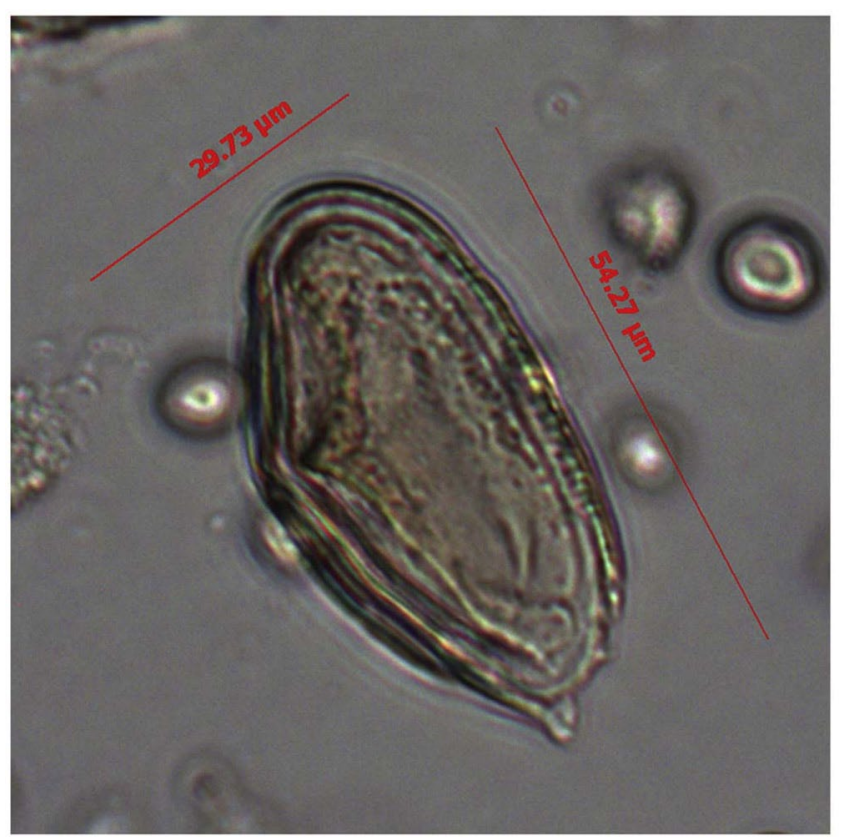

Fig. 2. Enterobius vermicularis egg from Pueblo Bonito. This egg is poorly preserved, but it is clearly identifiable by morphology and visible parasite larva.

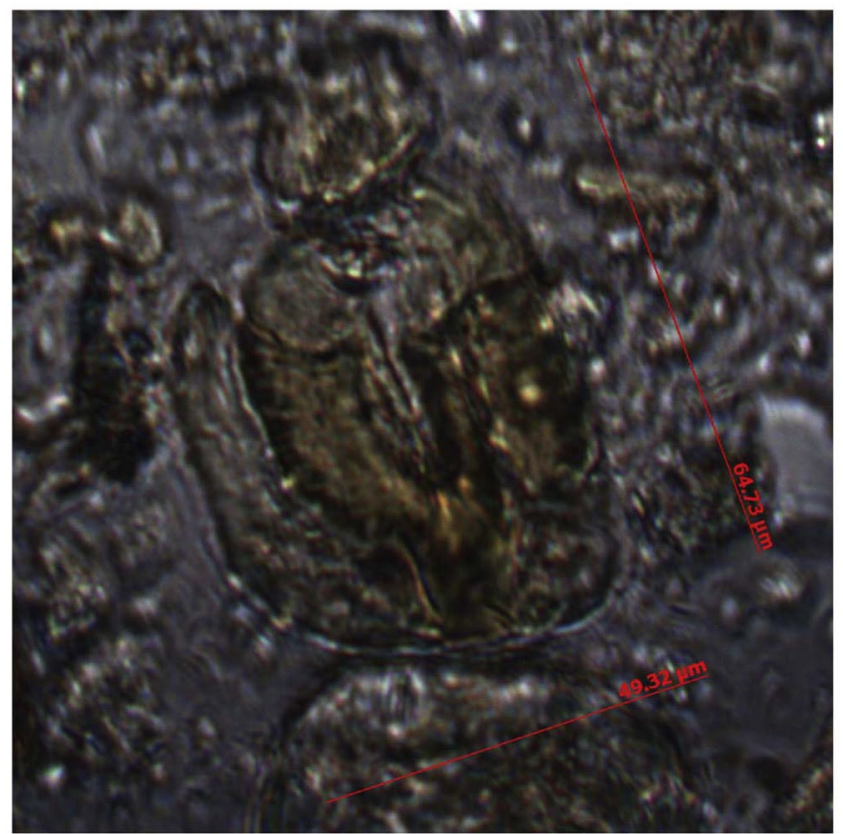

Fig. 3. Poorly preserved larval nematode from Atlatl Cave. Morphologically, this larva resembles a juvenile (L1) stage of the hookworm Ancylostoma duodenale, but the overall dimensions are likely too small to be of this species.

the larvae of the hookworm Ancylostoma duodenale or the threadworm Strongyloides stercoralis (Figs. 3-5), but poor preservation prevented definitive identification. These specimens may be parasite larvae, but we are unable to rule out the possibility that they are freeliving nematodes that colonized the feces following their deposition. 


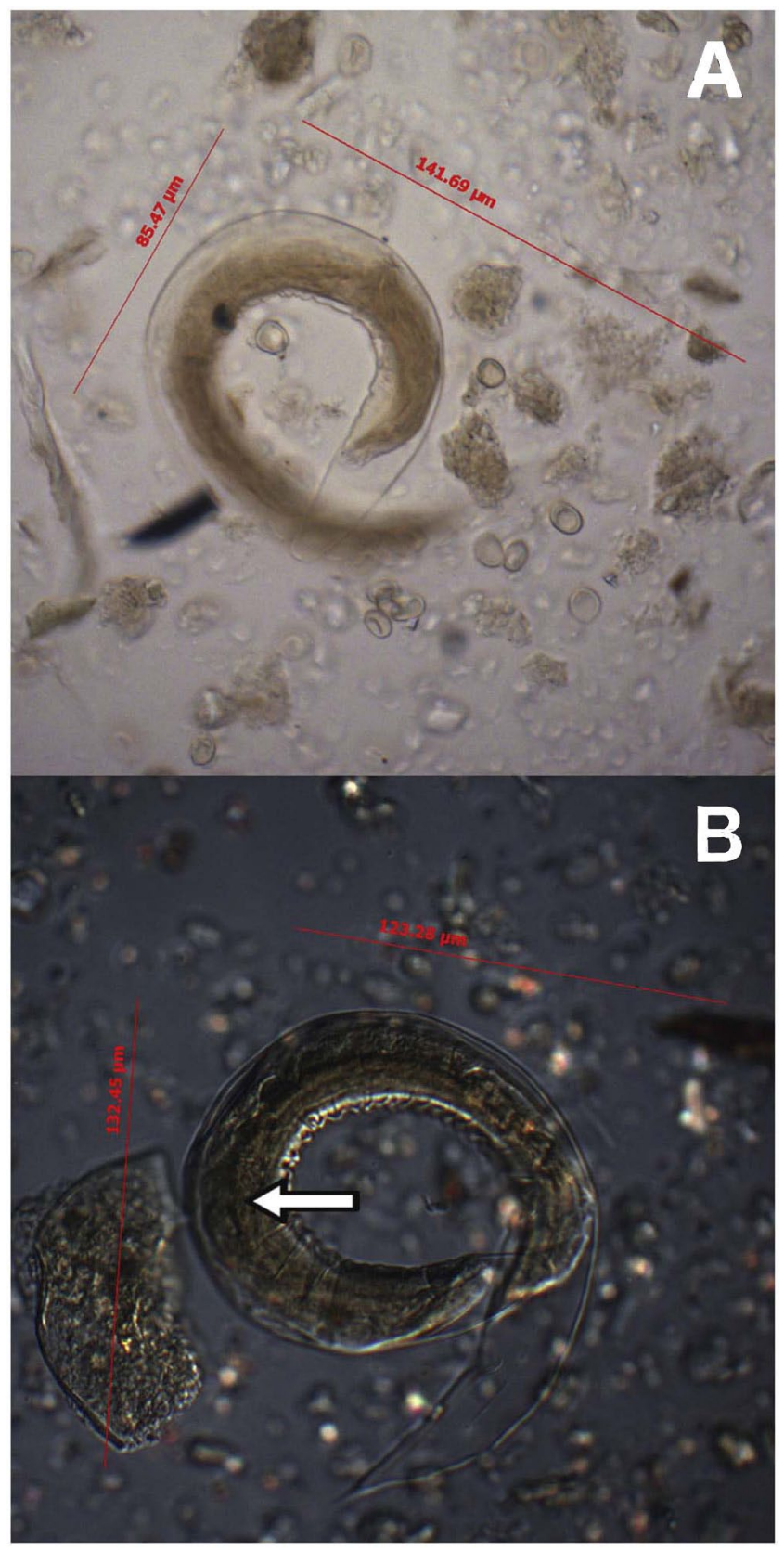

Fig. 4. Rhabditiform nematode larvae from Pueblo Bonito. These larvae shrank within their cuticles during desiccation and resemble those observed by Reinhard and Clary (1986). We believe they are a free-living species. The esophagus-intestine juncture (b, marked by arrow) is located at a third of the total body length, a characteristic of Strongyloides stercoralis rhabditiform larvae. However, the curved intestine and presence of a cuticle do not suggest that this is S. stercoralis. The larvae are too short to be $A$. duodenale, and tail morphology is not consistent with this species.

Our methods were nearly identical to those used in a previous analysis of Chaco Canyon coprolites (Reinhard and Clary, 1986), and we summarized all available data on the archaeoparasitology of Chaco Canyon (Table 4). 


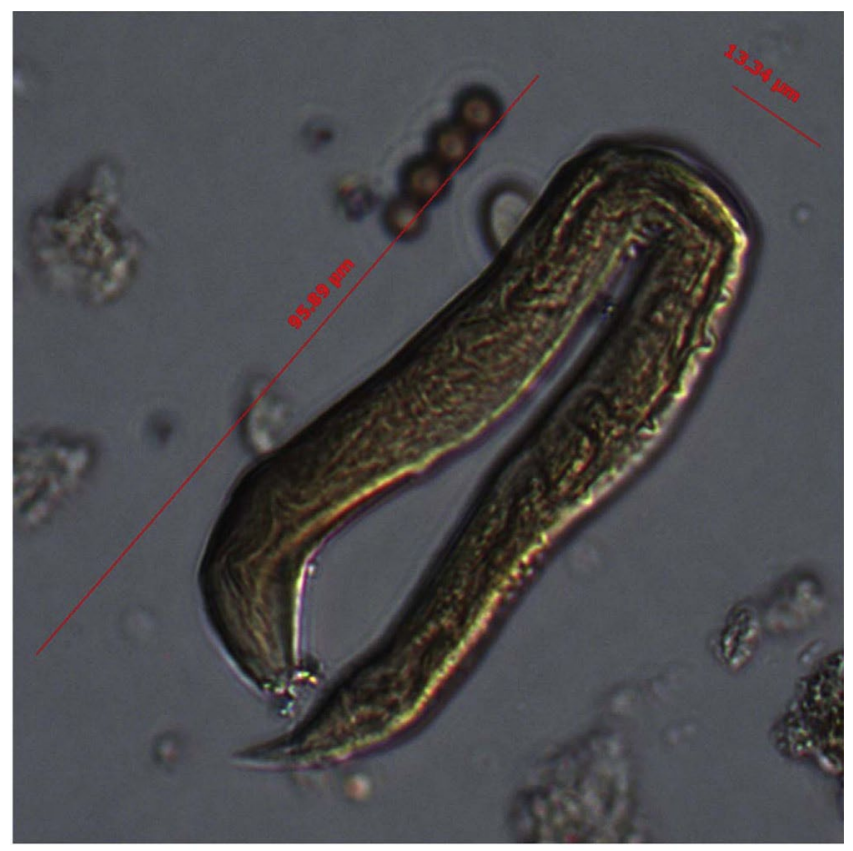

Fig. 5. Filariform nematode larva from Pueblo Bonito. This larva resembles the infective stage (L3) of A. duodenale. However, the curved intestine and body length may be indicative of a freeliving species.

Table 4 Summary of all archaeoparasitology data from Chaco Canyon coprolites. The first number in each cell indicates the number of coprolites analyzed in this study, and the parenthesized number indicates the total number of coprolites examined when the work of Reinhard and Clary (1986) is included.

\begin{tabular}{lccccc} 
Site & $\begin{array}{c}\text { Coprolite } \\
\text { dates }\end{array}$ & $\begin{array}{c}\text { Number of } \\
\text { coprolites } \\
\text { analyzed }\end{array}$ & $\begin{array}{c}\text { Trichuris } \\
\text { trichiura } \\
\text { (whipworm) }\end{array}$ & $\begin{array}{c}\text { Enterobius } \\
\text { vermicularis } \\
\text { (pinworm) }\end{array}$ & $\begin{array}{c}\text { Unidentified } \\
\text { larval } \\
\text { nematodes }\end{array}$ \\
\hline Pueblo Alto & $1050-1100 \mathrm{CE}$ & $2(4)$ & - & - & - \\
Pueblo Bonito & $920-1164 \mathrm{CE}$ & $10(23)$ & $1(1)$ & $2(6)$ & $2(5)$ \\
Kin Kletso & $1100-1150 \mathrm{CE}$ & $4(9)$ & - & $1(1)$ & - \\
Atlatl Cave & $1926-1751$ cal. BCE & $2(2)$ & $1(1)$ & - & $1(1)$ \\
\hline
\end{tabular}

\section{Discussion}

\subsection{Whipworm in North America}

Our findings represent the earliest record of the human whipworm, Trichuris trichiura, from North America (1926-1751 cal. BCE). T. trichiura coevolved with human hosts in Africa, and its range expanded to other continents through human migration (Hawash et al., 2016). 
South American records indicate that this species has been present in the New World for at least 8000 years (Gonçalves et al., 2003), but until now there were no North American records older than 1400 years before present (Jiménez et al., 2012).

The timing and route by which $T$. trichiura and the hookworms Ancylostoma duodenale and Necator americanus first reached the New World have been the topic of substantial debate (e.g., Araújo et al., 2008, 1988; Hawdon and Johnston, 1996; Reinhard et al., 2001). These three parasites are host-specific, so human migration is the only mechanism by which range expansion may occur. Because these three species also require warm, moist, shaded soil for the development of eggs or larvae to complete their life cycles, some authors have asserted that whipworm and hookworm could not have crossed Beringia and instead must have reached the Americas through coastal or oceanic migration (Araújo et al., 2008). Our new record of T. trichiura at Chaco Canyon can neither support nor refute hypotheses for specific human migration routes to the Americas, but this addition to the archaeoparasitological record can contribute to continued conversations on how and when humans and their parasites reached the New World.

\subsection{Whipworm in the Southwest}

Extensive prior archaeoparasitology research on the Southwest shows that $T$. trichiura was nearly absent from this region, which has been attributed to the arid climate and a lack of contact with infected Mesoamerican cultures (Reinhard, 1992, 1990). We present new records of $T$. trichiura infection at both a Late Archaic site (Atlatl Cave, 1926-1751 cal. BCE) and an Ancestral Puebloan great house (Pueblo Bonito, 1039-1163 cal. CE). These records raise questions about the historical events and cultural conditions that led to the arrival and the persistence of this parasite at Chaco Canyon.

The transmission and survival of $T$. trichiura in a human host population are dependent on contact with moist, shaded soil at moderate temperatures. $T$. trichiura follows a direct life cycle in which adult worms living in the host's cecum mate and release undeveloped eggs with the host's feces. Under appropriate environmental conditions, the eggs embryonate in soil, hatch into larvae, and mature through several larval forms before they are ingested by a subsequent host, 
usually through fecal contamination of food or water (Roberts and Janovy, 2008). Experimental embryonation studies have determined that eggs of $T$. trichiura will not survive high temperatures, desiccation, or direct sunlight (Beer, 1976; Brown, 1927). The environmental constraints on $T$. trichiura transmission are also evident in the modern global distribution of the species, which is limited by aridity and extreme temperatures (Bundy and Cooper, 1989; Pullan and Brooker, 2012).

Modern Chaco Canyon is a desert with great variation in both temperature ( -38 to $106^{\circ} \mathrm{F}$ ) and annual precipitation ( 85 to $458 \mathrm{~mm}$ ) (Mathien, 2005). Pollen records indicate that desert shrub grassland has characterized Chaco Canyon for at least the last 10,000 years (Hall, 1988), so it is likely that similar temperature and precipitation ranges existed during Archaic and later prehispanic human occupancy of the region. Given the ecological requirements of T. trichiura, it is unlikely that sustained transmission of the parasite could have occurred at Chaco Canyon under natural conditions. This is consistent with the absence of the species at most other Southwestern archaeological sites for which parasitological analysis has been completed (Reinhard, 1990). The rarity of other common soil-transmitted parasites (the hookworm Ancylostoma duodenale and the threadworm Strongyloides stercoralis) from the Southwest (Gonçalves et al., 2003) suggests that soil-dependent transmission was likely inhibited by regional environmental conditions.

The lone prior record of ancient $T$. trichiura in the Southwest is from the Sinagua site at Elden Pueblo, with latrine soils dated from 1070 to 1250 CE (Reinhard et al., 1987). Like Chaco Canyon, Elden Pueblo may have been too dry to sustain the full life cycle of T. trichiura. However, archaeological and zooarchaeological data suggest that residents of Elden Pueblo migrated seasonally to spend cooler months in the Verde River Valley located 50 miles to the south. This annual migration to a wetter environment may explain the persistence of $T$. trichiura at Elden Pueblo (Reinhard et al., 1987).

In the case of Chaco Canyon, two requirements must have been met to lead to the whipworm infections we observed at Atlatl Cave and Pueblo Bonito. First, contact with an infected population must have occurred, which may have been accomplished through interactions with Mesoamerican cultures. The second requirement for the 
transmission and persistence of $T$. trichiura in this arid region is anthropogenic alteration of the local environment. We will discuss each of these requirements in the context of the infection we observed at both Late Archaic and Ancestral Puebloan sites.

\subsection{Late Archaic infection: whipworm at Atlatl Cave}

The eggs of Trichuris trichiura from the Atlatl Cave coprolite (19261751 cal. BCE) represent the first record of parasitism among Late Archaic inhabitants of the Colorado Plateau. Prior to this study, the lone Archaic site on the Colorado Plateau examined for parasites was Dust Devil Cave in southeastern Utah, occupied from 6800 to 4600 years ago (Reinhard et al., 1987). No parasite remains were observed in the analysis of 100 coprolites from Dust Devil Cave. This led to the suggestion that a nomadic, hunter-gatherer lifestyle led to a low risk of parasitic infection when compared to later records from Ancestral Puebloan settlements. Only two coprolites from Atlatl Cave were available for our study, and one contained T. trichiura eggs. A more extensive analysis of coprolites from this site would offer a more resolved picture of Late Archaic parasitism at Chaco Canyon, but our results confirm that infection with $T$. trichiura occurred among inhabitants of Atlatl Cave.

Atlatl Cave is a crescent shaped cave approximately 25 meter long, 4-5 meter deep, and 2-5 meter high (Mathien, 2005). It was named for a broken atlatl found alongside a yucca sandal, remnants of a rabbit-fur robe, pictographs, stone points, and various other artifacts. These materials and radiocarbon dating indicate intermittent use by Late Archaic hunter-gatherers and early agriculturalists practicing a mixed subsistence strategy from 4855 to 2405 years before present (Elliott, 1986; Gillespie, 1982; Mathews and Neller, 1979). There are several cliff pour-offs in this section of the canyon, and Elliott (1986) points to the presence of a natural basin below the shelter and the nearby occurrence of natural seeps. We surmise that moist soil and insulation from extreme temperatures and direct sunlight within Atlatl Cave may have provided an environment conducive to whipworm transmission.

Whipworm infection among Late Archaic inhabitants of Atlatl Cave may have been facilitated by contact with cultures in Mesoamerica, 
where environmental conditions were more favorable for infection. Archaeoparasitological data from Mesoamerica are limited to one study on coprolites from the Zape region of Durango, Mexico (Jiménez et al., 2012). This record of the Loma San Gabriel culture indicates that a diverse parasite community, including T. trichiura, was present in Mesoamerica 1400 years ago. Zape is considered to be at the interface of Mesoamerican and Southwestern cultures, so interaction among residents of these two regions could have contributed to the northward movement of T. trichiura. Because no earlier records of Mesoamerican parasitism are available and the whipworm we found at Atlatl Cave predates the Zape record by> 2000 years, we cannot make a definitive link between Mesoamerican infection and the arrival of the parasite at Chaco Canyon. However, given the available evidence, we believe that the most likely route by which whipworm traveled to Chaco Canyon at the time of Atlatl Cave occupation was through contact with Mesoamerican cultures.

A similar pathway from Mesoamerica to the Southwest has been used to explain the northward movement of another parasite species, the hookworm Ancylostoma duodenale (Jiménez et al., 2012). Hookworm was established in Mesoamerica as early as 1400 years ago, predating the earliest records from the Southwest by at least 500 years (Jiménez et al., 2012). The transfer of hookworm from Mesoamerica to the Colorado Plateau suggests early contact and interaction between cultures in these regions, and it demonstrates the utility of parasites as markers for ancient human movement and interaction, as proposed by Araújo et al. (2008). If parasitism can indeed be taken as evidence for ancient human migration and cultural interaction, then records of hookworm and whipworm both support a hypothesis for early interaction between Southwestern and Mesoamerican societies. In the case of whipworm at Atlatl Cave, we suggest that this contact occurred as early as 1926-1751 cal. BCE. This timeframe is consistent with evidence of Late Archaic maize agriculture at Chaco Canyon (Hall, 2010) and with other evidence of ideas, languages and cultigens diffusing north from Mesoamerica as early as 2500 BCE (Hill, 2001; Kemp et al., 2010; Merrill et al., 2009; Taube, 2000; Wills, 1995).

Once $T$. trichiura arrived at Chaco Canyon with its hosts, the parasite likely encountered multiple barriers to sustained transmission. The natural aridity and extreme temperatures of the region would 
have limited the parasite's survival during its soil-dwelling stages. Additionally, the diffuse, mobile populations expected of a huntergatherer society may not have aggregated in large enough numbers to facilitate parasite transmission. Both of these potential pitfalls for the parasite may have been alleviated through a shift in susceptible host populations away from a strictly hunter-gatherer lifestyle. More sedentary populations, in which potential hosts congregated for longer periods of time and at higher densities, would have increased the chance of parasite transmission. Maize agriculture occurred near Atlatl Cave as early as 3940 years before present (Hall, 2010), which suggests that a shift toward a more sedentary lifestyle was occurring in the region at the time of the cave's occupation. Local environmental alteration associated with agriculture may also have promoted parasite transmission if it led to increased soil moisture through irrigation or the application of night soil as fertilizer. The details of Late Archaic maize cultivation at Chaco Canyon are not well known, but we surmise that environmental modifications made by early agriculturalists to facilitate crop success may also have facilitated whipworm transmission.

If transitions toward a sedentary, agricultural lifestyle enhanced the persistence of whipworm infection among early residents of Chaco Canyon, this supports earlier hypotheses on relationships between cultural development and parasitism. Cockburn (1971) proposed that disease patterns in ancient human populations followed human cultural evolution. As humans became more sedentary, altered their environments to produce food, and increased in population density, barriers to infectious disease transmission that accompanied a hunter-gatherer lifestyle diminished. Reinhard (1988) explored this hypothesis via analyses of parasitological data from the Colorado Plateau and demonstrated that occasional infections present in hunter-gatherers became more severe among agricultural peoples. At the time, Reinhard argued that hunter-gatherers were largely free of the infectious disease risks faced by sedentary populations. At first appraisal, our record of whipworm infection among Late Archaic residents of Atlatl Cave seems to contradict the Cockburn-Reinhard hypothesis. However, if we view the early maize agriculturalists of Atlatl Cave as a step along the path to a settled lifestyle, we may be witnessing a transition toward greater infection risk that is consistent with the Cockburn-Reinhard hypothesis. Overall, we believe that the presence of $T$. 
trichiura at Atlatl Cave reflects early interaction with Mesoamerican cultures and provides evidence for a relationship between parasite infection and cultural development.

\subsection{Puebloan infection: whipworm and pinworm at Pueblo Bonito}

One coprolite from Pueblo Bonito dated from 1039 to 1163 cal. CE contained eggs of $T$. trichiura. This is the first record of T. trichiura from an Ancestral Puebloan great house despite extensive coprolite analysis in past studies (Reinhard, 2008a, 2008b, 1990). We also observed eggs of the pinworm, Enterobius vermicularis, in two coprolites from Pueblo Bonito and Kin Kletso. Pinworm has been observed previously from Pueblo Bonito coprolites (Reinhard and Clary, 1986), and it was common across the prehispanic Southwest (Reinhard, 1990).

Like whipworm, pinworm is an intestinal nematode that is transmitted through a direct life cycle. Pinworm transmission differs from whipworm in that gravid females deposit eggs while crawling throughout the host intestine and anus, and many of these eggs remain on the perianal skin rather than leaving the body with the host's feces (Roberts and Janovy, 2008). For this reason, fecal analysis does not reliably identify all infected hosts within a population. Coprolite analysis revealed approximately 25\% pinworm infection prevalence at both Pueblo Bonito and Kin Kletso, but the actual prevalence of infection was likely higher. Pinworm causes little pathology, but since it shares a fecal-oral transmission pattern with many other parasites and pathogens, heavy infection at Ancestral Puebloan sites suggests that these populations may have harbored other infectious diseases (Reinhard, 2008a). Given the high prevalence of pinworm at Chaco Canyon great houses, it is surprising that whipworm has been observed only once in the analysis of 36 coprolites.

Several potential barriers to whipworm transmission may have limited infection among Ancestral Puebloans, including Chaco Canyon's geographical isolation. Although $T$. trichiura was present among Late Archaic inhabitants of Chaco Canyon, we do not know whether the parasite persisted locally during the 3000 year gap between the records at Atlatl Cave and Pueblo Bonito. Unless the residents of Atlatl Cave were the direct ancestors of Ancestral Puebloans, it seems 
unlikely that whipworm would have been endemic at Chaco Canyon during this entire period. It is more plausible that whipworm infected Ancestral Puebloan populations as a result of interaction with Mesoamerican cultures. Whipworm infection at Zape 1400 years ago preceded the infection we observed at Pueblo Bonito by several centuries. We posit that the presence of whipworm at Pueblo Bonito in 10391163 cal. CE adds to earlier evidence, including cacao and macaws (Watson et al., 2015; Crown and Hurst, 2009), for the interaction of Ancestral Puebloans at Chaco Canyon with Mesoamerican cultures.

Human behavior and culture were also likely important to the persistence of $T$. trichiura infection among Ancestral Puebloans at Chaco Canyon. Anthropogenic alteration of the local environment through the construction of large, apartment-style dwellings and irrigation agriculture may have promoted whipworm infection by establishing moist, shaded areas in which eggs and larvae could develop. Within great houses, shaded rooms may have provided an appropriate environment for parasite transmission, especially if paired with seasonal moisture derived from monsoons or snowmelt. However, whipworm infection at great houses may also have been controlled by parasitelimiting strategies such as defined sanitation, preference of open space for activities, and consumption of anthelminthic plants (Reinhard and Pucu, 2014). Despite large population sizes at Chaco in general, perhaps great houses were not very crowded, or hygienic conditions for the elites occupying these sites limited whipworm transmission (Reinhard, 2008b).

High pinworm and low whipworm infection prevalence provide dueling support for and against the Cockburn-Reinhard hypothesis. While heavy pinworm infection at great houses suggests that residents encountered crowded, unsanitary conditions conducive to parasite transmission, the rarity of whipworm infection demonstrates that cultural development does not always increase the risk of infection for all parasite species. Because whipworm requires specific environmental conditions to complete its life cycle, it may have been easier to control than pinworm, which has relatively simple transmission requirements. We conclude that relationships between cultural development and infectious disease are not always obvious or unidirectional, and the unique ecological requirements of different parasites and pathogens are important to the nature of these relationships. 


\subsection{Other potential parasite species at Chaco Canyon}

Several coprolites from Atlatl Cave and Pueblo Bonito contained nematode larvae that we were unable to identify morphologically due to poor preservation (Table 1, Figs. 3-5). These larvae are not T. trichiura or E. vermicularis. They resemble the hookworm Ancylostoma duodenale or the threadworm Strongyloides stercoralis, but they may also be free-living worms that colonized the feces after deposition. Without definitive identification of these nematodes, we cannot comment on their significance at Chaco Canyon. Reinhard and Clary (1986) reported similar nematode larvae from Pueblo Bonito. The nematodes were not definitively identified at the time, but the authors noted their resemblance to $S$. stercoralis. This has led to some confusion about the presence of both $S$. stercoralis and A. duodenale in the Chaco Canyon parasite record (Gonçalves et al., 2003; Reinhard, 2008a). After careful examination of the larval nematodes observed in this study and a review of the information presented by Reinhard and Clary (1986), we do not have sufficient evidence to support the record of either $A$. duodenale or S. stercoralis at Chaco Canyon. The problem of poor larval and adult parasite preservation in archaeological materials supports the need for the development of molecular techniques in archaeoparasitology (e.g., Leles et al., 2008).

\subsection{Conclusions}

Whipworm infected human inhabitants of Chaco Canyon in both Late Archaic and Ancestral Puebloan times, as early as 1926-1751 cal. BCE at Atlatl Cave and as late as 1039-1163 cal. CE at Pueblo Bonito. The presence of whipworm in a setting that is both geographically isolated and climatically arid suggests that early residents of Chaco Canyon met all of the requirements for the species' survival, and perhaps that transmission of the species is more robust to adverse conditions than previously believed. Ancient records of T. trichiura on the Colorado Plateau generally support two interpretive applications of archaeoparasitology. First, parasitological data can be used to trace ancient human migration and cultural interactions across large areas, consistent with the 'parasites as probes' idea proposed by Araújo et al. (2008). Second, parasitic infection follows cultural development 
within a region, as proposed by both Cockburn (1971) and Reinhard (1988). However, the effects of these transitions on parasitic infection are not always obvious or unidirectional. Overall, our results demonstrate the utility of parasitological analysis of archaeological materials to understanding the health and habits of ancient cultures and that cultural context is important to the establishment and persistence of parasitic disease.

Acknowledgments - The coprolites analyzed in this study were provided by the Chaco Culture National Historical Park Museum Collection. The University of Nebraska-Lincoln, College of Arts and Sciences provided funding for radiocarbon dating. We thank Scott Gardner for allowing us to photograph parasites at the Harold W. Manter Laboratory of Parasitology, University of Nebraska-Lincoln. We thank Adauto Araújo, Martín Fugassa, Scott Gardner, and Agustín Jiménez for confirming our identification of $T$. trichiura eggs and for their comments on larval nematode identification. Comments from Terry Haverkost, members of the Morin Laboratory at Rutgers University, editor Andy Howard, and two anonymous reviewers led to the improvement of this manuscript. REP received support from the National Science Foundation Graduate Research Fellowship Program (DGE-1433187). The authors declare that they have no conflict of interest.

\section{References}

Araújo, A., Ferreira, L.F., Confalonieri, U., Chame, M., 1988. Hookworms and the peopling of America. Cad. Saude Publica (2), 226-233. http://dx.doi. org/10.1590/S0102-311X1988000200006.

Araújo, A., Reinhard, K.J., Ferreira, L.F., Gardner, S.L., 2008. Parasites as probes for prehistoric human migrations? Trends Parasitol. 24, 112-115. http://dx.doi. org/10.1016/j.pt.2007.11.007.Copyright.

Beer, R., 1976. The relationship between Trichuris trichiura (Linnaeus 1758) of man and Trichuris suis (Schrank 1788) of the pig. Res. Vet. Sci. 20, 47-54.

Bronk Ramsey, C., 2013. OxCal 4.2.4. Web Interface Build (78).

Brown, H.W., 1927. Studies on the rate of development and viability of the eggs of Ascaris lumbricoides and Trichuris trichiura under field conditions. J. Parasitol. 14, 1-15.

Bundy, D.A.P., Cooper, E.S., 1989. Trichuris and trichuriasis in humans. Adv. Parasitol. 28, 107-173.

Callen, E., Cameron, T., 196o. A prehistoric diet revealed in coprolites. New Sci. 8, 35-40.

Cameron, C.M., 2001. Pink chert, projectile points, and the Chacoan Regional System. Am. Antiq. 66, 79-102. 
Clary, K.H., 1983. Prehistoric Coprolite Remains From Chaco Canyon, New Mexico: Inferences for Anasazi Diet and Subsistence. University of New Mexico, Albuquerque.

Clary, K.H., 1984. Anasazi diet and subsistence as revealed by coprolites from Chaco Canyon. In: Judge, W., Schelberg, J. (Eds.), Recent Research on Chaco Prehistory. Reports of the Chaco Center No. 8 Division of Cultural Research, National Park Service, Albuquerque, pp. 265-279.

Clary, K.H., 1987. Coprolites from Pueblo Alto. In: Mathien, F.J., Windes, T.C. (Eds.), Investigations at the Pueblo Alto Complex, Chaco Canyon, New Mexico, 1975-1979. Artifactual and Biological Analyses. Publications in Archaeology 18F, Chaco Canyon Studies, vol. III. National Park Service, Santa Fe, New Mexico, pp. 785-788.

Cockburn, T.A., 1971. Infectious diseases in ancient populations. Curr. Anthropol. $12,45-62$.

Confalonieri, U.E., Ribeiro-Filho, B.M., Ferreira, L.F., Araujo, A.J.G., 1985. The experimental approach to paleoparasitology: desiccation of Trichuris trichiura eggs. Paleopathol. Newsl. 51, 9-11.

Crown, P.L., Hurst, W.J., 2009. Evidence of cacao use in the Prehispanic American Southwest. Proc. Natl. Acad. Sci. 106, 2110-2113.

Duff, A.I., Moss, J.M., Windes, T.C., Kantner, J., Shackley, M.S., 2012. Patterning in procurement of obsidian in Chaco Canyon and Chaco-era communities in New Mexico as revealed by X-ray florescence. J. Archaeol. Sci. 30, 2995.2007.

Elliott, M., 1986. Atlatl Cave and the Late Archaic Period in Chaco Canyon. University of New Mexico, New Mexico.

Fry, G.F., 1977. Analysis of Prehistoric Coprolites from Utah. University of Utah Anthropological Papers 97 (Salt Lake City).

Gillespie, W.J., 1982. Vertebrate Remains From Atlatl Cave, New Mexico. University of New Mexico, Albuquerque.

Gonçalves, M.L.C., Araújo, A., Ferreira, L.F., 2003. Human intestinal parasites in the past: new findings and a review. Mem. Inst. Oswaldo Cruz 98, 103-118.

Hall, S.A., 1988. Prehistoric vegetation and environment at Chaco Canyon. Am. Antiq. 53, 582-592.

Hall, S.A., 2010. Early maize pollen from Chaco Canyon, New Mexico, USA. Palynology 34, 125-137. http://dx.doi.org/10.1080/01916121003675746.

Hawash, M.B.F., Betson, M., Al-Jubury, A., Ketzis, J., LeeWillingham, A., Bertelsen, M.F., Cooper, P.J., Littlewood, D.T.J., Zhu, X.-Q., Nejsum, P., 2016. Whipworms in humans and pigs: origins and demography. Parasit. Vectors 9. http://dx.doi. org/10.1186/s13071-016-1325-8.

Hawdon, J.M., Johnston, S.A., 1996. Hookworms in the Americas: an alternative to trans- Pacific contact. Parasitol. Today 12, 72-74. http://dx.doi. org/10.1016/0169-4758(96)80658-2.

Heitman, C.C., Van Dyke, R., Peebles, M., Boczinsky, K., 2016. Greater Chaco Landscapes Great House Communities GIS Integration Dataset. GIS Dataset Submitted to the National Park Service in Partial Fulfillment of Rocky Mountain 
Cooperative Ecosystems Study Unit Task Agreement Number: P14ACo1703, Project \#: UCOB-109.

Hill, J.H., 2001. Proto-Uto-Aztecan: a community of cultivators in Central Mexico? Am. Anthropol. 103 (4), 913-934. http://dx.doi.org/10.1073/pnas.0905753107.

Hugot, J.P., Reinhard, K.J., Gardner, S.L., Morand, S., 1999. Human enterobiasis in evolution: origin, specificity and transmission. Parasite 6, 201-208.

Hull, S., Fayek, M., Mathien, F.J., Roberts, H., 2014. Turquoise trade of the Ancestral Puebloan: Chaco and beyond. J. Archaeol. Sci. 45, 187-195. http://dx.doi. org/10.1016/j.jas.2014.02.016.

Irwin-Williams, C., 1973. The Oshara Tradition: Origins of Anasazi Culture. Contributions in Anthropology 5(1). Eastern New Mexico University, Portales, New Mexico.

Jiménez, F.A., Gardner, S.L., Araújo, A., Fugassa, M., Brooks, R.H., Racz, E., Reinhard, K.J., 2012. Zoonotic and human parasites of inhabitants of Cueva de los Muertos Chiquitos, Rio Zape Valley, Durango, Mexico. J. Parasitol. 98, 304-309. http://dx.doi.org/10.1645/GE-2915.1.

Kemp, B.M., Gonzalez-Oliver, A., Malhi, R.S., Monroe, C., Schroeder, K.B., McDonough, J., Rhett, Gl, Resendez, A., Peñaloza-Espinosa, R.I., Buentello-Malo, L., Gorodesky, C., Smith, D.G., 2010. Evaluating the farming/language dispersal hypothesis with genetic variation exhibited by populations in the Southwest and Mesoamerica. Proc. Natl. Acad. Sci. 107 (15), 6759-6764.

Kincaid, C. (Ed.), 1983. Chaco Roads Project, Phase I: A Reappraisal of Prehistoric Roads in the San Juan Basin. United States Department of the Interior, Bureau of Land Management, Albuquerque and Santa Fe.

Lekson, S.H., 1984. Great Pueblo Architecture of Chaco Canyon, New Mexico. National Park Service, Albuquerque, New Mexico.

Leles, D., Araújo, A., Ferreira, L.F., Vicente, A.C.P., Iñiguez, A.M., 2008. Molecular paleoparasitological diagnosis of Ascaris sp. from coprolites: new scenery of ascariasis in pre-Columbian South America times. Mem. Inst. Oswaldo Cruz 103, 106-108. http://dx.doi.org/10.1590/So074-02762008005000004.

Marshall, M.P., Stein, J.R., Loose, R.W., Novotny, J.E., 1979. Anasazi Communities of the San Juan Basin. Public Service Company of New Mexico, Albuquerque and New Mexico State Historic Preservation Bureau, Santa Fe.

Mathews, T.W., Neller, E., 1979. Atlatl Cave: Archaic-basketmaker II investigations in Chaco Canyon National Monument. In: Linn, R.M. (Ed.), Proceedings of the First Conference on Scientific Research in the National Parks. National Park Service Transactions and Proceedings Series No. 5, Washington, D.C, pp. 873.

Mathien, F.J., 2005. Culture and Ecology of Chaco Canyon and the San Juan Basin. National Park Service, Santa Fe, New Mexico.

McKenna, P.J., Truell, M.L., 1986. Small Site Architecture of Chaco Canyon, New Mexico. National Park Service, Santa Fe, New Mexico.

Merrill, W.L., Hard, R.J., Mabry, J.B., Fritz, G.J., Adams, K.R., Robey, J.R., MacWilliams, A.C., 2009. The diffusion of maize to the Southwestern United States and its impact. Proc. Natl. Acad. Sci. 106 (50), 21019-21026. http://dx.doi. org/10.1073/pnas.0906075106. 
Mills, B.J., Ferguson, T.J., 2008. Animate objects: shell trumpets and ritual networks in the greater southwest. J. Archaeol. Method Theory 15 (4), 338-361.

Nials, F.L., Stein, J.R., Roney, J.R., 1987. Chacoan Roads in the Southern Periphery: Results of Phase II of the BLM Chaco Roads Project. Cultural Resources Series No. 1 United States Department of the Interior, Bureau of Land Management, Albuquerque.

Powers, R.P., Gillespie, W.B., Lekson, S.H., 1983. The Outlier Survey: A Regional View of Settlement in the San Juan Basin. Reports of the Chaco Center, No. 3 U. S. Department of the Interior, National Park Service, Division of Cultural Research, Albuquerque, New Mexico.

Pullan, R.L., Brooker, S.J., 2012. The global limits and population at risk of soiltransmitted helminth infections in 2010. Parasit. Vectors 5. http://dx.doi. org/10.1186/1756-3305-5-81.

Reinhard, K.J., 1988. Cultural ecology of prehistoric parasitism on the Colorado Plateau as evidenced by coprology. Am. J. Phys. Anthropol. 77, 355-366. Reinhard, K.J., 1990. Archaeoparasitology in North America. Am. J. Phys. Anthropol. 82, 145-163.

Reinhard, K.J., 1992. Parasitology as an interpretive tool in archaeology. Am. Antiq. 57, 231-245.

Reinhard, K.J., 2008a. Parasite pathoecology of Salmon Pueblo and other Chacoan Great Houses: the healthiest and wormiest Ancestral Puebloans. In: Reed, P.F. (Ed.), Chaco's Northern Prodigies: Salmon, Aztec, and the Ascendancy of the Middle San Juan Region After AD 1100. University of Utah Press, pp. 456.

Reinhard, K.J., 2008b. Pathoecology of two Ancestral Pueblo villages. In: Reitz, E.J., Scarry, C.M., Scudder, S.J. (Eds.), Case Studies in Environmental Archaeology. Springer, pp. 191-209. http://dx.doi.org/10.1007/978-0-387-71303-8 10 .

Reinhard, K.J., Bryant, V.M., 1992. Coprolite analysis: a biological perspective on archaeology. Archaeol. Method Theory 4, 245-288.

Reinhard, K.J., Bryant, V.M., 2006. Pathoecology and the future of coprolite studies in bioarchaeology. In: Stodder, A.W.M. (Ed.), Reanalysis and Reinterpretation in Southwestern Bioarchaeology. Arizona State University Press, Tempe, pp. 199-216.

Reinhard, K.J., Clary, K.H., 1986. Parasite analysis of prehistoric coprolites from Chaco Canyon, New Mexico. In: Akins, N. (Ed.), A Bioarchaeological Approach to Human Burials from Chaco Canyon, New Mexico. Reports of Chaco Center Number 9 National Park Service, Santa Fe, pp. 177-186.

Reinhard, K.J., Pucu, E., 2014. Comparative parasitological perspectives on epidemiologic transitions: the Americas and Europe. In: Modern Environments and Human Health: Revisiting the Second Epidemiologic Transition, pp. 311-326. http://dx.doi.org/10.1002/9781118504338.ch17.

Reinhard, K.J., Confalonieri, U.E., Herrmann, B., Ferreira, L.F., Araújo, A., 1986. Recovery of parasite remains from coprolites and latrines: aspects of paleoparasitological technique. Homo 37, 217-239.

Reinhard, K.J., Hevly, R.H., Anderson, G.A., 1987. Helminth remains from prehistoric Indian coprolites on the Colorado Plateau. J. Parasitol. 73, 630-639. 
Reinhard, K., Araújo, A., Ferreira, L.F., Coimbra, C.E.A., 2001. American hookworm antiquity. Med. Anthropol. 20, 96-101. http://dx.doi.org/10.1080/01459 740.2001.9966190.

Roberts, L., Janovy, J.J., 2008. Foundations of Parasitology, 8th ed. McGraw-Hill, New York.

Taube, K., 200o. Lightning celts and corn fetishes: the Formative Olmec and the development of maize symbolism in Mesoamerica and the American Southwest. In: Studies in the History of Art. 58. pp. 296-337.

Thienpont, D., Rochette, F., Vanparijs, O.F.J., 1979. Diagnosing Helminthiasis Through Coprological Examination. Janssen Research Foundation, Beerse.

Toll, M.S., 1981. Macro-botanical remains recovered from Chaco Canyon coprolites. In: Technical Series 38. Castetter Laboratory for Ethnobotanical Studies. Department of Biology, University of New Mexico, Albuquerque.

Toll, H.W., 1991. Material distributions and exchange in the Chaco System. In: Crown, P.L., Judge, W.J. (Eds.), Chaco and Hohokam Prehistoric Regional System in the American Southwest. School of American Research Press, Santa Fe, New Mexico, pp. 7-107.

Watson, A.S., Plog, S., Culleton, J.C., Gilman, P.A., LeBlanc, S.A., Whiteley, P.M., Claramunt, S., Kennett, D.J., 2015. Early procurement of scarlet macaws and the emergence of social complexity in Chaco Canyon, NM. Proc. Natl. Acad. Sci. $112,8238-8243$.

Wills, W.H., 1995. Archaic foraging and the beginning of food production in the American Southwest. In: Last Hunters-first Farmers: New Perspectives on the Prehistoric Transition to Agriculture, pp. 215-242. 